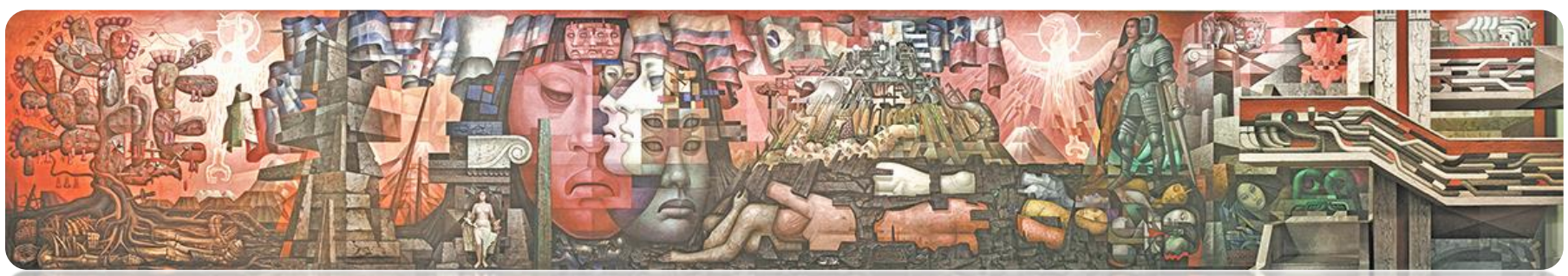

Rev. Hist., N²8, vol. 2, Julio-Diciembre 2021: 241-270

ISSN 0717-8832

https://doi.org/10.29393/RH28-33CFMA20033

\title{
Construcción de femineidad durante el proceso de industrialización en Lota: una revisión del periódico “La Opinión” (1924-1962) *
}

Femininity construction during the industrialization process in Lota: a revision of the newspaper "La Opinión" (1924-1962)

Mary Anne Argo Chávez** Alejandra Brito Peña***

\section{RESUMEN}

La industria carbonífera de Lota transformó las dinámicas entre patrones y familias, generando nuevas relaciones con el género femenino fuera de los espacios laborales. La presente investigación realiza un análisis sobre la construcción de la identidad de género femenina en Lota a través del discurso expuesto por la Compañía Minera e Industrial de Chile en el periódico local "La Opinión". Se busca comprender la producción de este medio de prensa, expresión del paternalismo industrial, con la finalidad de revisar si este responde a una práctica de disciplinamiento cultural por parte de la empresa carbonífera de Lota.

Palabras clave: Historia de género, Paternalismo industrial, Identidad de género, Análisis de prensa, Disciplinamiento cultural y Lota industrial.

\footnotetext{
* Proyecto PIA-CONICYT SOC1403 y Proyecto Fondecyt № 1200806.

** Antropóloga con mención en Antropología Sociocultural y Magíster en Historia. Analista de datos proyecto UCM2095 Universidad Católica del Maule. ORCID: https://orcid.org/0000-0002-2513-7172. Correo electrónico: margo@ucm.cl

*** Historiadora - Licenciada y Magíster en Historia, Doctora en Estudios Americanos. Docente e Investigadora de los Dptos. de Sociología y de Historia de la Udec. ORCID:https://orcid.org/0000-0001-5279-5982. Correo electrónico: abrito@udec.cl
} 


\begin{abstract}
The Industrialization process in the coal mining industry in Lota transformed the dynamics between bosses and employees, generating new relationships with the female gender beyond the workspace. This research analyzes the construction of the female gender identity in Lota through the discourse given by the Compañía Minera e Industrial de Chile in the local newspaper "La Opinión". The main purpose of this investigation is to understand the production of this press medium through an industrial paternalism logic in order to review it and define whether it was a cultural discipline mechanism generated by Lota's coal industry or not.
\end{abstract}

Key Words: Gender History, Industrial paternalism, Gender identity, Press analysis, Cultural discipline and Industrial Lota.

Recibido: marzo 2020

Aceptado: octubre 2020

\title{
Introducción
}

El proceso de industrialización que se inicia en Chile en el siglo XIX permitió la incorporación de nuevas tecnologías en actividades productivas. En Chile, destacan industrias de variado rubro, tales como textiles, carboníferas, salitreras, etc., que se desarrollaron en este período y que trajeron consigo una serie de cambios para sus trabajadores/as tanto a nivel laboral, como en el ámbito privado o personal, modificando enormemente sus formas de vida y las dinámicas sociales existentes. La industrialización más allá de solo traer innovaciones tecnológicas y la necesidad de aprender nuevas técnicas, reconfiguró los espacios, las normas y las disciplinas laborales ${ }^{1}$. Este determinismo tecnológico ${ }^{2}$ se tradujo en el desarrollo de nuevas relaciones laborales sustentadas en las ideas del Paternalismo Industrial surgido en Europa, donde el obrero y su cuerpo son vistos como máquinas y/o engranajes que conforman la máquinasistema productiva y que está marcado por nuevas disciplinas laborales verticales, donde el patrón ejerce dominación y el obrero subordinación ${ }^{3}$. El Paternalismo no solo apuntaba a la producción, sino que también a la configuración de un tejido social construido en torno a la actividad productiva y en base a códigos morales, creencias, conductas y percepciones definidas por el patrón como las idóneas según su definición de un "obrero modelo" ${ }^{4}$, la cual también iba

\footnotetext{
1 Vergara, Ángela. 2013. "Paternalismo industrial, empresa extranjera y campamentos mineros en América Latina: un esfuerzo de historia laboral y transnacional", en Avances del Cesor, Año X, No 10, Rosario, p. 118

2 Sierra, José. 1990. El obrero soñado: Ensayos sobre el paternalismo industrial (Asturias, 1860-1917), Madrid, Siglo veintiuno editores, p.21

3 Ídem.

4 Ídem., p.80.
} 
en coherencia con el desarrollo del modelo capitalista, las formas de vida asociadas a este, los imaginarios y estereotipos de género, laborales y morales de la época.

La relación entre los obreros y sus patrones experimentó transformaciones, que articularon los espacios de trabajo en las industrias de forma distinta ${ }^{5}$. Los patrones buscaron tener a sus trabajadores cerca en todo momento y buscaron los mecanismos para que gozaran de buen ánimo y salud; mientras que los obreros se adhirieron a las políticas implementadas por éstos y se apropiaron de estas instancias, llegando a exigirlas como un derecho. Los obreros migraban con sus familias a las cercanías de las industrias, creándose ciudades industriales en torno a las faenas productivas, dentro de las cuales el eje central era la industria.

Esta nueva forma de vincularse, fue configurando relaciones de poder entre patrones y obreros, afectando el desarrollo social de ambos no solo en lo laboral, sino que también en todos los aspectos de la vida (educación, familia, religión, salud, entre muchos otros). A través del Paternalismo Industrial, el patrón-padre velaba por el obrero-hijo y su familia, volviéndose indispensable para que el obrero pudiera desarrollar su vida dentro y fuera de los espacios de trabajo ${ }^{6}$. Así, se creó un verdadero modelo de "Familia Industrial", cuyas actividades laborales y de ocio eran generadas y reguladas por la industria, determinando parámetros basados en la ocupación habitacional, las interacciones sociales, las relaciones de género, la moralidad y/o las creencias $^{7}$. Todos estos mecanismos generados o mediados por la industria buscaban generar el disciplinamiento del obrero y/o, en este caso, de su familia, asegurando así su permanencia y garantizando la productividad y reproducción de estos en la máquina-sistema laboral ${ }^{8}$. La transformación de los obreros y familias se daba a través de mecanismos de disciplinamiento en relaciones asimétricas de poder ${ }^{9}$ marcadas por relaciones de docilidad-sometimiento, donde el disciplinamiento cultural ocurría a través del control de los cuerpos sociales y la desarticulación y rearticulación de las distribuciones de los espacios físico-temporales laborales y de ocio.

Según lo anterior, la empresa ejerció acción de forma directa e indirecta en todo ámbito, extendiéndose esta influencia más allá de la relación patrón-obrero, abarcando al resto de la familia industrial (hijos, hijas y/o cónyuge del obrero). Se crearon modelos de lo que era considerado apropiado o correcto para los distintos miembros del núcleo familiar, usualmente ligados a las actividades promovidas u ofrecidas por la misma industria. Se instauraron políticas

\footnotetext{
${ }^{5}$ Vergara. 2013. "Paternalismo industrial", p. 114.

${ }^{6}$ Sierra. 1990. El obrero soñado, p. 62.

7 Ídem, p.121.

8 Ídem, p.10

9 González, Yanko. 2007. "Servicio militar obligatorio y disciplinamiento cultural: Aproximación al caso HuillicheMapuche siglo XXI", en ALPHA, $\mathrm{N}^{\circ} 24$, Osorno, p. 117.
} 
sociales de índole intervencionista ${ }^{10}$ que permitieron definir en base a objetivos sociales específicos lo esperado para cada sector de la población a través de la planificación, socialización y reconstrucción de estos. Se desarrolló el concepto de "seguridad social" 11 entregándole al obrero en complemento a su salario real, que estaba conformado por el acceso a beneficios tales como educación, salud, espacios de ocio, condiciones de vida que no era del fácil acceso para los obreros de la época. Así, la industria garantizaba un desarrollo idóneo de su capital humano (obreros), de su capital humano futuro (niños, niñas y jóvenes) y la permanencia de estos en las ciudades industriales ${ }^{12}$ a través del disciplinamiento cultural, entendido este como la adecuación física, valórica y moral de la familia industrial. En este contexto, surge como un tema de interés la situación particular de las mujeres, usualmente invisibilizadas como sujetos relevantes para este tipo de investigaciones ${ }^{13}$, más aún si se considera que tuvieron una gran influencia, tanto directa como indirecta, en el desarrollo de todos los ámbitos en el caso de Lota industrial.

La incorporación de las mujeres a los distintos procesos sociales, - como su participación en movimientos obreros ${ }^{14}$ y su incipiente incorporación al mundo laboral - generaron cambios en la concepción preexistente sobre su propio género y su relación con el género masculino, particularmente desde la perspectiva de patrones e industrias. Participaron siempre en un espacio intermedio ${ }^{15}$, no dentro de la mina pero sí ligadas a ésta de forma indirecta. Su influencia se construía desde el ámbito familiar, algunas veces también, ligadas al ámbito laboral realizando labores "aceptadas" para su sexo, según los estereotipos de la época (labores administrativas, alimenticias, de modista, etc.).

Con esta investigación buscamos reconstruir las ideas en torno a las identidades de género expuestas por la industria carbonífera, particularmente aquellas dirigidas hacia las mujeres. Para este fin, se definió estudiar los productos culturales de la época ya que estos fueron el reflejo de la sociedad en la que fueron creados $^{16}$. En específico se realizó una revisión exhaustiva del periódico "La Opinión" de Lota, principalmente debido a la disponibilidad de la fuente y a la extensión de su publicación.

\footnotetext{
${ }^{10}$ Foucault, Michel. 2009. Nacimiento de la Biopolítica. Cursos en el "College de France" (1978-1979). Editorial Akal, p. 106.

11 Ídem.

12 Ídem.

13 Figueroa, Consuelo. 2009. Revelación del subsole: Las mujeres en la sociedad minera del carbón 1900-1930. Editorial ICSO Diego Portales, Chile, p. 28.

14 . Ídem

15 Figueroa. 2009. Revelación del subsole, p. 29.

${ }^{16}$ Butler, Judith. 2002. Cuerpos que importan. Sobre los límites materiales y discursivos del sexo, Barcelona, Paidós, p. 43.
} 
La metodología que se utilizó en esta investigación fue la revisión de prensa ${ }^{17}$. Este periódico fue publicado por la Compañía Minera e Industrial de Chile desde los años 1924 a 1962 e impreso en una imprenta de la ciudad de Concepción. Era distribuido gratuitamente los días domingo e incluía información sobre las zonas de Lota, Retiro, Coronel, Plegarias y Curanilahue, aunque se centraba principalmente en la primera. Fue producido y distribuido por la carbonífera de Lota, aunque no fue publicado entre los años 1963 a 1967. No fue posible encontrar información respecto al motivo del cese de su publicación durante esos años, aunque según algunos documentos, aparentemente habría vuelto a circular durante el año 1967. Sobre la disponibilidad de la fuente, ésta se encuentra desde su primer año de publicación en 1924 hasta previo al cese de ésta en febrero de 1962. Se revisó el material desde sus inicios hasta el último ejemplar conocido y disponible. Cabe mencionar que la frecuencia de publicación disminuyó con los años (reduciéndose a sólo un ejemplar mensual), lo cual afectó su cobertura informativa.

Para analizar el periódico, se realizó un análisis de contenido ${ }^{18}$ en base a un índice temático de todos sus años de publicación. Se revisaron los distintos artículos del periódico, poniendo especial atención en las secciones y/o apartados que fueron dirigidos explícitamente al género femenino y masculino. Se identificó cada artículo con un eje temático (ej: "Deportes", "Salud", "Educación", etc.) determinados a priori. Estas fueron establecidas tanto para el género femenino como el masculino, debido al formato del presente artículo, lo referido al género masculino solo se menciona a modo general y en función de aquellas para el género femenino.

\section{Contextualización histórica y el rol de las mujeres en el Lota industrial}

La historia de la industria carbonífera de Lota se remonta a los inicios de las actividades de extracción de carbón en la zona. Astorquiza y Galleguillos (1952) ${ }^{19}$ en "Cien años del carbón de Lota", narran la obtención de las escrituras de las minas de Lota por parte de Matías Cousiño, quién participó en el desarrollo del ferrocarril en Caldera y Copiapó y quien se interesó por el carbón debido a su creciente importancia ${ }^{20}$. La familia Cousiño estuvo a cargo de esta industria, ya sea de forma directa o indirecta. En la Región del Biobío Lota no fue de las primeras localidades en las que se explotó el carbón; la primera fue Schwager, luego Talcahuano y Lirquén, posteriormente Penco y, finalmente, Lota, probablemente debido a que sus minas están en el subsuelo marino (encontrándose a una profundidad de 200 y 100 metros aproximadamente). La compañía, hasta el año 1962, pasó por cuatro cambios de nombre desde su creación:

\footnotetext{
17 Bardin, Laurence. 1977. El análisis de contenido, Madrid, Editorial Akal, p. 34.

${ }^{18}$ Aróstegui, Julio. 1995. La investigación histórica, teoría y método, Barcelona, Editorial Crítica, p. 408.

${ }^{19}$ Astorquiza, Octavio y Galleguillos, Óscar. 1952. Cien años del carbón de Lota 1852-1952, Compañía carbonífera e industrial de Lota, Lota, Chile.

20 Ídem, pp. 57.
} 
1. “Compañía de Lota" (1852 - 1870)

2. “Compañía explotadora de Lota y Coronel (1870 - 1904)

3. “Compañía de Lota y Coronel (1905 - 1920)

4. “La compañía minera e industrial de Chile" (1921 - 1932)

5. “La compañía carbonífera e industrial de Lota” (1933)

Lota se convierte en una ciudad industrial con la presencia del ferrocarril y el desarrollo de la industria carbonífera. Esto llevó a una cantidad importante de personas a migrar a la zona a trabajar, trasladándose con sus familias a las casas entregadas por la carbonífera, lo que contribuyó a cambiar el foco de las dinámicas sociales, las actividades económicas y el ocio de los habitantes del territorio. Godoy ${ }^{21}$ indica que los primeros trabajadores llegaron a Lota desde el Norte Chico entre 1875 y 1900 debido a que hubo una crisis productiva del cobre, además de que en Lota se requería mano de obra especializada para la actividad minera. La presencia de la carbonífera se dividía espacialmente en Lota Alto y Lota Bajo. En el primero se encontraba la industria minera y la ciudad erigida a su alrededor por la compañía, allí estaba el centro cívico, mercado, teatro, parroquia, correo, oficina de bienestar, entre otros. En Lota Bajo se encontraban las instituciones y edificaciones correspondientes a municipios, autoridades propias de una ciudad" 22 el comercio "al detalle" y varias escuelas

A nivel de organización interna, la industria se organizaba en cargos en orden descendente: Directorio, Gerencia y Administración General. En la última sección se encontraban los jefes de los distintos departamentos (Departamento de Minas, Electricidad, Tracción y Maquinaria, Preparación Carbón, Arquitecto, Seguridad, Mecánica, Jefe Maestranza, Estudios, Contable, Embargo, Judicial y Bienestar).

Respecto al rol de las mujeres en Lota industrial, es importante mencionar que la incorporación del enfoque de género es más bien reciente en la historia sobre la clase trabajadora minera chilena. La que se ha centrado en relevar el protagonismo masculino. Klubock ${ }^{23}$ menciona que desde el sentido común se define la construcción de identidad de género masculina en base a la masculinidad minera como la esencial y que esto dificulta generar definiciones que incorporen componentes culturales, sociales, políticos etc., que a su vez incluyan a las mujeres.

\footnotetext{
${ }^{21}$ Godoy, Milton. 2015. "Las casas de la empresa: Paternalismo industrial y construcción de espacio urbano en Chile. Lota, 1900-1950", en Revista Universum N 1, Vol. 30, Talca, pp. 120.

${ }^{22}$ Astorquiza, y Galleguillos. 1952. Cien años del carbón de Lota, pp. 90.

${ }^{23}$ Klubock, Thomas. 1995. "Hombres y mujeres en el Teniente: La construcción de género y clase en la minería chilena del cobre, 1904-1951", en Disciplina y desacato. Construcción de identidad en Chile, siglos XIX y XX, Santiago, Editorial SUR/CEDEM, pp.110-123.
} 
Figueroa ${ }^{24}$, por su parte, indica que el tejido social lotino presentaba dos esferas centrales: la inferior o pública y la superior o privada. En la inferior se realizaba el trabajo, donde estaba la mina. Este nivel era considerado el principal, ya que al ser Lota una ciudad minera, todo giraba en torno al trabajo; esta era la esfera pública dominada por el género masculino. Por otro lado, la esfera superior, correspondía al género femenino y albergaba la esfera privada, de la familia y del hogar. La autora además, hace una distinción entre dos estereotipos bastante marcados para las mujeres: "La mujer buena" y "La mujer mala" ${ }^{25}$. La primera se rige por los estereotipos impuestos tradicionalmente (casa, familia y la limpieza), cumpliendo de manera óptima su rol en la sociedad. En contraposición, "la mujer mala" no cumple con estas imposiciones y por tanto se la consideraba "sucia y peligrosa", generaba desorden de la estructura, de las condiciones sanitarias y de los ideales sociales.

En el contexto industrial minero la salud jugaba un rol central para la productividad. Aspectos como la distribución de los espacios y la regulación constante de los aspectos sanitarios a nivel individual, familiar y laboral (entendidas estas acciones dentro de una lógica higienista ${ }^{26}$ ) actuaron como un mecanismo de control donde el rol de la mujer fue central. El hogar como espacio se definió en base a su orden y limpieza cuya organización estaba liderada por las mujeres. Godoy indica que la precariedad de las viviendas fue un problema mayúsculo en la primera mitad del siglo XX, donde el excesivo hacinamiento (un promedio de diez personas en habitaciones de tres por tres metros) y falta de condiciones higiénicas generó estragos sanitarios, al exponer a los trabajadores y sus familias a múltiples enfermedades ${ }^{27}$. En el periódico analizado, se difundían campañas de sanitización de los espacios y el hogar, higiene personal, alimentación sana, concientización e información sobre las enfermedades, vías de contagio y propagación. Además, se ponía especial énfasis en el rol de la mujer como encargada de mantener un estado óptimo de limpieza, sanidad física y buen estado generalizado de su familia y hogar. En Lota la sanidad estaba a cargo del Servicio de Salud, el Hospital de Lota y el Policlínico, cuya tutela estaba a cargo del Departamento de Bienestar.

La Industria Minera y Carbonífera de Lota fue la primera en tener un Departamento de Bienestar industrial ${ }^{28}$. Este era el encargado de generar los espacios para el desarrollo de actividades, trabajo y/o enseñanza de lo que se esperaba de las mujeres lotinas. Los Departamentos de Bienestar surgieron como entidades para la entrega de "estímulos sociales" 29 o "beneficios" a cambio del trabajo de los obreros, con la finalidad de mantener

\footnotetext{
${ }^{24}$ Figueroa. 2009. Revelación del subsole, p.29.

25 Ídem.

${ }^{26}$ Foucault. 2009. Nacimiento de la Biopolítica, p. 105.

27 Godoy. 2015. "Las casas de la empresa", p. 126.

28 Illanes, María Angélica. 2001. "Ella en Lota-Coronel: poder y domesticación: el primer servicio social industrial de América Latina", Mapocho Revista de Humanidades y Ciencias Sociales, N4 49, Santiago, pp. 144.

29 Ídem.
} 
buenas relaciones entre el patrón y el obrero y evitar los desórdenes o revueltas sociales. Sennet plantea que el paternalismo industrial o empresarial buscaba amalgamar simbólicamente las esferas laborales y familiares en una sola ${ }^{30}$. Así, las políticas asistencialistas permitían generar esta unión, aumentar la productividad y evitar el descontento. En este panorama, el Paternalismo se definió como una dinámica de poder donde los varones continuaban dominando, aunque no necesariamente asegurando bienes materiales o herencia a su descendencia, pero desarrollando un papel protector para con sus hijos e hijas (en este caso, el padre-patrón y los hijos-obreros) y, para legitimar su poder, para lo cual se utilizaban símbolos y creencias $^{31}$. Así, el Departamento de Bienestar lotino surgió como una institución que le permitió a la industria desarrollar políticas asistencialistas, y reproducir creencias y simbolismos deseados por la industria para los distintos miembros de la familia industrial. Desde el discurso de la industria, el bienestar social era un aspecto casi tan importante como la "marcha industrial":

"Con la experiencia de los años se ha llegado a la conclusión de que una de las bases de la estabilidad de la industria la constituye el bienestar social que hoy, prácticamente, vela por el trabajador desde el nacimiento hasta su muerte. Las diversas etapas de la vida de un individuo están marginadas en los servicios de bienestar." ${ }^{32}$

La industria se vanagloriaba de tener el mejor servicio de bienestar del país y de invertir grandes sumas de dinero en este, publicando los recursos que se gastaban cada año ${ }^{33}$. Este departamento fue creado por Carlos Cousiño en 1922 indicando que este habría venido a "solucionar los más difíciles problemas surgidos del trabajo" ${ }^{34}$. Se planteó como un espacio que buscaba el bienestar de los trabajadores, a fin de reducir los conflictos sociales, que abundaban en la época donde fue creado. Su estrategia se basaba en elementos "técnico y social, moral e intelectual” 35 que implicó la contratación de personal, la creación de instituciones, espacios de esparcimiento y la compra de artículos necesarios para la familia. En la descripción de estas políticas en base a su plan integral ${ }^{36}$, el componente económico jugaba un rol que, para la industria era importante visibilizar. A las dueñas de casa se las mencionaba sólo al referirse al control de los precios del mercado y del restaurante económico por parte de la industria. Para

\footnotetext{
${ }^{30}$ Sennet, Richard. 1982. La Autoridad, Madrid, Editorial Alianza, p. 65.

${ }^{31}$ Sennet. 1982. La Autoridad, pp. 58

${ }^{32}$ Astorquiza y Galleguillos. 1952. Cien años del carbón de Lota, p. 209

33 Ídem, pp. 211.

${ }^{34}$ Astorquiza y Galleguillos. 1952. Cien años del carbón de Lota, p. 212.

35 Ídem.

${ }^{36}$ Plan integral definido y descrito como tal por los autores de "Cien años del carbón". Astorquiza y Galleguillos. 1952. Cien años del carbón de Lota, p. 213.
} 
el desarrollo de sus funciones esenciales el Departamento de Bienestar ${ }^{37}$ tenía las siguientes secciones: Contratación de obreros, Habitación y servicios anexos, Servicio Social, Aprovisionamiento del personal, Servicio médico y Hospital, Escuelas, publicaciones, biblioteca, Sociabilidad, deportes, distracciones, Previsión social y accidentes de trabajo. Quienes actuaron como la bisagra que permitía el buen funcionamiento de este engranaje industrial, fueron las visitadoras sociales; ellas fueron las profesionales encargadas de poner en funcionamiento el Departamento de Bienestar.

Las visitadoras sociales, según María Angélica Illanes ${ }^{38}$ desarrollaron una política social para el control y manejo de la relación entre barbarie-civilización. La autora identifica tres tipos de barbarie: 1) Miseria, mortalidad de los niños, pobreza y ciudades pobres (para los intelectuales y clase trabajadora), 2) Movimiento obrero que amenaza el orden establecido (para la clase dirigente y religiosa) y 3) El militarismo del Estado y la burguesía ejercido por las clases dirigentes (para los obreros). Estos sectores "incivilizados" desde la visión de la clase dirigente debían ser "civilizados", para lo cual se generaron acciones profesionalizadas hacia los sectores más vulnerables que articularon la intervención social-popular a través del trabajo de las Visitadoras Sociales. De este modo:

"En este contexto, la "política social" tenderá a profesionalizar la intervención civil y estatal sobre los pobres en particular y los trabajadores y el pueblo en general, con el objeto de hacerlos funcionales a los objetivos de producción (de riqueza), de reproducción (ideológicocultural) de la civilización moderna o de mayor o menor democratización de las estructuras por la vía política, es decir, no represiva /no revolucionaria." ${ }^{39}$

De esta manera, a principios del siglo XX se generó un giro en las políticas dirigidas hacia la clase trabajadora. Se transitó desde un marco político excluyente a políticas inclusivas, cumpliendo objetivos funcionales a las necesidades o expectativas de la clase dirigente. Esta política social debía ser aplicada y aquí entran en juego las "Mujeres Visitadoras", las que "encarnan y aplican las directrices de la política social" ${ }^{40}$. María Angélica Illanes ${ }^{41}$ nos muestra las vivencias de la primera visitadora social de Lota, Berta R. De Abadie, reconstruyendo a su vez su trabajo con las distintas organizaciones femeninas que fueron creadas por el Departamento de Bienestar. La figura de la visitadora social buscaba solucionar problemas de índole social en los hogares mineros o, en palabras de lllanes, "reparación-reorganización de la

\footnotetext{
37 Ídem.

38 Illanes, María Angélica. 2006. Cuerpo y sangre de la política: La construcción histórica de las visitadoras sociales (1887-1940). Ediciones LOM, Chile.

39 Illanes. 2006. Cuerpo y sangre de la política, p.14.

40 Illanes. 2006. Cuerpo y sangre de la política, p.17.

41 Illanes. 2001. "Ella en Lota-Coronel", p. 141-148.
} 
miseria obrera del carbón" ${ }^{42}$ a través de tres mecanismos centrales: 1)"Regeneración" del obrero como padre, 2) Reorganización de las fuerzas productivas al interior del hogar y, 3) Facilitar la obtención de mejoramientos familiares revisando el historial de comportamiento del obrero. La visitadora se localizaba en el espacio intermedio entre el obrero y la industria, haciendo de mediadora entre los espacios públicos y privados, por un lado el empleo, y el hogar por otro. Personificó la estrecha relación patrón-familia obrera, logrando que la industria ingresara de lleno al espacio del hogar familiar, convirtiéndose así en un mecanismo central de disciplinamiento-domesticación del mundo privado. Lo anterior, sumado al mejoramiento de las condiciones habitacionales de los trabajadores y la creación de otras políticas y espacios sociales, le permitió a la industria generar un discurso de preocupación, interés y cuidado por el bienestar de sus obreros y familias. Así, se visibilizaba en distintos artículos del periódico como "el buen patrón" o "la buena industria" 43.

Las organizaciones femeninas, según Figueroa ${ }^{44}$, cumplían el rol de reafirmar los estereotipos de género y desarrollar un tejido social permeado por estos. Illanes describe las organizaciones sociales femeninas existentes en la época ${ }^{45}$. Estas fueron creadas por el Departamento de Bienestar a través de la gestión de Berta, la primera Visitadora Social de Lota:

1. La Liga de las Madrecitas: Grupo de niñas en edad escolar pertenecientes a la Escuela de niñas "Isidora Cousiño", las que se reunían para recibir enseñanza de cómo atender a los lactantes. Las reuniones eran semanales e impartidas por el médico del hospital. También recibían charlas y conferencias de miembros de la Gota de Leche y de la misma Visitadora.

2. Gota de Leche: Servicio dirigido principalmente a mujeres embarazadas y sus hijos e hijas por nacer y/o nacidos; comenzó a funcionar con la llegada de Berta a Lota.

3. Centro femenino de Lota "Patria y Hogar": Asociación social femenina dirigida a las señoras de mineros.

4. Cruz roja juvenil: Fundada por la visitadora social Berta en unión con el centro femenino "Patria y hogar". Este estaba destinado a las socias del centro y sus hijas. Una enfermera capacitaba a este cuerpo asistencial y tenían acción en el hospital.

5. Escuela nocturna para mujeres adultas: Fundada también por Berta en conjunto con el centro femenino "Patria y Hogar". Este buscaba educar a las mujeres y separarlas de sus antepasadas más ignorantes ${ }^{46}$

\footnotetext{
42 Ídem, pp. 147.

43 Término acuñado por las autoras de esta investigación.

${ }^{44}$ Figueroa. 2009. Revelación del subsole.

${ }^{45}$ Es importante mencionar que existieron más organizaciones femeninas pero las presentadas son aquellas que fueron gestionadas por el Departamento de Bienestar.

${ }^{46}$ Figueroa. 2009. Revelación del subsole, p.146.
} 
El trabajo de la Visitadora Social y los espacios femeninos intencionados por la industria, eran gestionados por el Departamento de Bienestar, desde allí también surgió el periódico "La Opinión" de Lota. A través de él se visibilizaban todos los eventos y actividades gestionados por este, además de presentar artículos de opinión moralizantes y ser un espacio mediante el cual sus lectores podían adquirir cierto protagonismo. Esto último a través de los concursos, las cartas al director y secciones que permitieron la apertura para desarrollar una comunicación entre la industria y la familia industrial que, aunque no era directa y no necesariamente tratara temas laborales, permitía un vínculo. El periódico constituyó el medio mediante el cual se visibilizaban las políticas asistencialistas y los intereses de la industria para con los miembros de la familia industrial. Permitía tener "evidencia" de cómo el "buen patrón" velaba por el bienestar de sus obreros y sus familias y sobre qué se esperaba de estos a cambio. Esto fue permeando las identidades de género de la época, proceso del que damos cuenta a continuación.

\section{Revisitando el Periódico “La Opinión” de Lota}

Se utilizó la metodología de análisis de contenido para el tratamiento de las fuentes ${ }^{47}$. Para estos fines se revisaron todos los números disponibles y se creó una base de datos con todos los artículos de interés para los objetivos de este trabajo ${ }^{48}$. Posteriormente se codificó la información temáticamente, es decir, se agruparon los artículos en base a categorías de análisis definidas para realizar análisis en mayor profundidad. Estas categorías fueron el segundo filtro de análisis, fueron determinadas a priori pero también se incorporaron categorías emergentes. Estas fueron: Madre-familia, Relación hombre-mujer, Dueña de hogar y Otros (artículos de temáticas variadas que aparecieron en menor frecuencia). Así llegamos a 472 artículos que hacían referencia a temas de género durante los 38 años de publicación del periódico.

De la totalidad de artículos, 331 hacen referencia solo al género femenino, es decir, un 70\%. El alto número de artículos haciendo alusión al género femenino indica una alta tendencia del periódico de tratar en base a su género a mujeres, mientras que los hombres no reciben el mismo tratamiento, refiriéndose a estos por su género solo para situaciones extraordinarias o para tratar temas específicos.

De este modo y en base a los artículos presentados, se reconstruyó el discurso en torno al género femenino presente en el periódico "La Opinión”, explicando cada categoría mencionada anteriormente. En la Imagen 1, se puede apreciar un primer acercamiento a los roles del género

\footnotetext{
${ }^{47}$ Bardin. 1977. El análisis de contenido, p. 34.

${ }^{48}$ Se consideró como artículos de interés para esta investigación todos aquellos que hacían alusión al género femenino explícitamente, independiente del tópico de este, y/o que hiciera alusión al género masculino diferenciándolo del género femenino o viceversa.
} 
femenino esperados para los inicios del siglo XX en Lota. En estos se evidencian los aspectos centrales (maternidad, administradora del hogar y compañera del hombre).

Imagen 1: Artículo del periódico que presenta la temática de "Rol femenino"

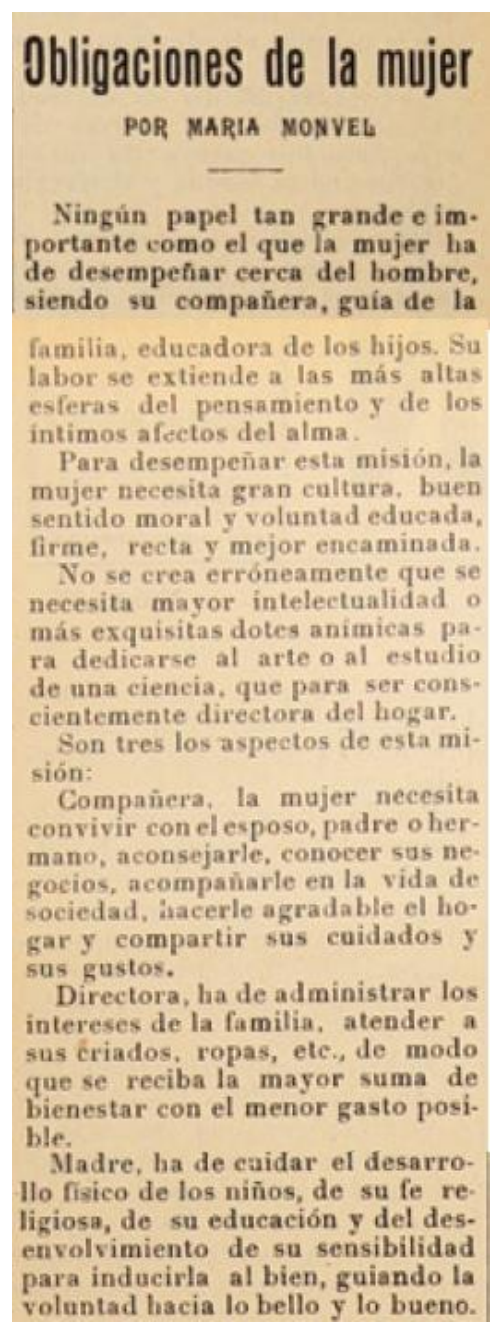

\section{OBLIGACIONES DE LA MUJER}

Por María Monvel.

Ningún papel tan grande e importante como el que la mujer ha de desempeñar cerca del hombre, siendo su compañera, guía de la familia, educadora de los hijos. Su labor se extiende a las más altas esferas del pensamiento y de los íntimos afectos del alma.

Para desempeñar esta misión, la mujer necesita gran cultura, buen sentido moral y voluntad educada, firme, recta y mejor encaminada.

No se crea erróneamente que se necesita mayor intelectualidad o más exquisitas dotes anímicas para dedicarse al arte $o$ al estudio de una ciencia, que para ser conscientemente directora del hogar. Son tres los aspectos de esta misión:

Compañera, la mujer necesita convivir con el esposo, padre o hermano, aconsejarle, conocer sus negocios, acompañarle en la vida de sociedad, hacerle agradable el hogar y compartir sus cuidados y sus gustos.

Directora, ha de administrar los intereses de la familia, atender a sus criados, ropas, etc. De modo que se reciba la mayor suma de bienestar con el menor gasto posible.

Madre, ha de cuidar el desarrollo físico de los niños, de su fe religiosa, de su educación y del desenvolvimiento de su sensibilidad para inducirla al bien, guiando la voluntad hacia lo bello y lo bueno.

"Periódico "La Opinión", núm. 45, 07 de junio 1925. Página 1 y 2. Impreso en Concepción.

Cabe mencionar que el género femenino, al cual se hace alusión en el periódico de manera más frecuente, es a las mujeres que conforman la familia industrial; es decir, las mujeres, hijas, madres y cónyuges de los obreros, por lo que los roles y simbolismos definidos a través del análisis de este periódico apuntaban a este grupo socio-económico en particular. Sobre las 
mujeres de clases sociales más altas, solo son mencionadas esporádicamente, en ocasiones se hacían artículos o entrevistas a personajes femeninos ilustres, siempre asociados al mundo académico-educativo, al mundo eclesiástico, de la salud y/o al mundo artístico. En general, estos ahondaron sobre la vida y obra de las mujeres mencionadas y no fueron considerados como parte del análisis temático más allá de considerar su existencia como antecedente de profesiones o áreas de interés para el género femenino por parte del discurso de la carbonífera.

En los artículos del periódico se indicaban los distintos roles y deberes que debían cumplir las mujeres. Se presentaban a modo de reglas, listas o imposiciones sin justificación sobre su motivo más que "debe ser así porque es el deber de las mujeres", por lo que se validaba la idea de que esta justificación estaría basada en la construcción de femineidad de la época. En base a esta revisión se establecen tres roles centrales: Madre, Dueña de hogar y compañera del hombre. En la siguiente Tabla se presentan las frecuencias:

Tabla 1. Tabla de frecuencias temáticas en artículos revisados

\begin{tabular}{l|c|c}
\hline & Frecuencia & Porcentaje \\
\hline Rol de madre & 29 & $37,1 \%$ \\
Dueña de hogar & 22 & $28,2 \%$ \\
Compañera del hombre & 14 & $17,9 \%$ \\
Otros & 13 & $16,6 \%$ \\
\hline TOTALES & 78 & $100 \%$ \\
\hline
\end{tabular}

Fuente: elaboración propia

En esta tabla se indica la frecuencia temática de los roles femeninos establecidos previamente, y la proporción del total de textos que corresponde a cada uno. A continuación analizaremos cada uno de ellos.

\section{Rol de la madre}

El rol de madre era el predominante, el que ha sido impuesto socio-culturalmente a las mujeres hasta los tiempos actuales, motivo por el cual no sorprende que este fuera el rol definido como el esencial también para las mujeres de Lota de la primera mitad el siglo XX. Lo anterior puede ser evidenciado en el fragmento de texto presentado en la Imagen 2, donde se indica que su rol es natural, histórico y parte del conocimiento colectivo. En base a su desempeño como madres se lograba establecer una diferencia entre las "buenas mujeres" y las "malas mujeres" ${ }^{49}$. Donde las primeras eran aquellas que atendían las necesidades de sus familias,

\footnotetext{
${ }^{49}$ Esta diferenciación aparece de forma explícita en los artículos del periódico en reiteradas ocasiones, además que fue mencionado en la bibliografía revisada. Debido a su frecuencia se utiliza como terminología a la cual se le atribuyen características específicas definidas en base al análisis. Figueroa. 2009. Revelación del subsole.
} 
particularmente de sus hijos e hijas, por sobre sus intereses personales, y las segundas aquellas que no se preocupaban de su familia o del hogar como era esperado de ellas y, por tanto, no cumplían sus deberes como mujeres.

Imagen 2: Artículo del periódico que presenta la temática de "Rol de madre"

\section{La mujer ante la vida}

Desde hace siglos, la actitud de la mujer ante la vida ha sido más que definida. La naturaleza nos lo demuestra y enseña, lo grita con su voz universal, esa voz que parece salir de lo más hondo de nuestra conciencia y que muchos pretenden no oir. Los hombres de ciencia y los sabios, que han sido portadores de esa voz única $y$ verdadera, estain de acuerdo en que la mís alta misión femenina es la maternidad. Es decir, que la mujer ha sido puesta en el mundo con el fin especial de la procreación y educación de los hijos.

Hay, sin embargo, gran cantidad de mujeres - y también de hombres - que niegan tal verdad, o por lo menos, no son partidarios de ella. Dicen estas personas que la maternidad es un estado inferior de la mujer por el cual pierde su libertad, ya que la educación y cuidado de la prole la esclaviza $y$ ocupa en todas las horas del dia.

Pero al decir esto caen en un error lamentable, error que es un resultado de la frivolidad $e$ inconstancia, que han hecho presa en los espíritus modernos. Hoy, para muchas mujeres, es un estorbo ser madres. Pero estas damiselas vaporosas no comprenden o no quieren comprender cuál es el verdadero papel que corresponde y debe desempeñar a cabalidad la mujer en el mundo.
LA MUJER ANTE LA VIDA

Desde hace siglos, la actitud de la mujer ante la vida ha sido más que definida. La naturaleza nos lo demuestra y enseña, lo grita con su voz universal, esa voz que aparece salir de lo más hondo de nuestra conciencia y que muchos pretenden no oír. Los hombres de ciencia y los sabios, que han sido portadores de esa voz única y verdadera están de acuerdo en que la más alta misión femenina es la maternidad.

Periódico “La Opinión”, núm. 293, 01 de octubre 1936. Página 11. Impreso en Concepción.

El rol de madre era el más importante para las mujeres $y$, como sostiene Valdivieso en su definición de las ciudadanas virtuosas, este es el rol que las hace indispensables para la sociedad: “(...) el principal rol que se le asigna es el de madre, solo a través de los hijos que tiene, cría y alimenta para la patria, llega a ser una madre heroica y gloriosa; se establece una identificación entre hijo heroico y madre heroica a su vez, es una ciudadana virtuosa" ${ }^{50}$. Esto se basa en la glorificación de la capacidad reproductiva femenina, que no es algo nuevo y que se basa en la comprensión de los géneros desde la biología. Rubinestablece que la capacidad de concebir tiene un alto componente sociocultural y político, ya que a través de la sangre se le permite a la humanidad trascender (en cuanto a sus bienes económicos, políticos y sociales), motivo por el cual en algunas culturas las mujeres comenzaron a usarse como un bien de

\footnotetext{
${ }^{50}$ Valdivieso, María Angélica. 2009. "Las mujeres y lo femenino en el discurso historiográfico: su contribución a la memoria y al imaginario social latinoamericano sobre la presencia de las mujeres en el espacio público", en XII Jornadas Interescuelas /Departamentos de Historia. Facultad de Humanidades y Centro Regional Universitario Bariloche. Universidad Nacional del Comahue, San Carlos de Bariloche, Argentina, pp. 9.
} 
intercambio para resolver asunto bélicos, hacer alianzas, etc. ${ }^{51}$. De aquí nace la idea del control del cuerpo femenino, que se hace extensiva a un sinnúmero de culturas, ya que controlar el cuerpo femenino y su capacidad reproductiva permite al hombre y a las culturas tener el control de la capacidad de reproducir su cultura y poder. En esto es importante recordar que tradicionalmente los roles de poder político eran masculinos, motivo por el cual este control biológico y cultural es ejercido desde el género masculino hacia el género femenino, en una relación de asimetría de poder que es intrínseca al entramado cultural y que se entiende como natural. Esta idea trascendió histórica y culturalmente, alimentando el imaginario de que el rol femenino esencial es el de madre con las labores asociadas a esa área, mientras que el rol masculino mantiene su rol de poder en esferas públicas (economía y política). En el caso del discurso presente en el periódico y profundizando la idea sobre la trascendencia sociocultural y política. Esto se evidenciaba en la asignación del rol de formadoras que se le entregaba a las mujeres, tanto en la crianza de los hijos e hijas, como en la importancia que se le otorgaba a su rol como educadoras, al fomentar los valores y creencias de las formas de vida industriales.

Siguiendo con la construcción del imaginario de la madre desde su origen histórico, Montecino ${ }^{52}$ plantea que el valor simbólico de la madre en Latinoamérica está relacionado con la dicotomía entre "la madre presente y el padre ausente", donde el desarrollo del mestizaje entre "indios" y conquistadores dio lugar al nacimiento de muchos hijos ilegítimos (huachos) o no reconocidos de los cuales tuvieron que hacerse cargo solo las madres. Así se definió a la madre como presencia y al padre como ausencia, motivo por el cual su rol es más que solo biológico, es también cultural ya que el único referente de los mestizos era su madre ${ }^{53}$. Por este motivo en Latinoamérica y en particular en Chile, la construcción del imaginario femenino se basa en esta presencia de la madre como la encargada del proceso de endoculturación de los hijos e hijas, es decir, de la crianza. Esto se evidencia en el discurso del periódico a través de la importancia que se le da a la Puericultura a través de distintas secciones específicas para este fin ("Charlas de Puericultura", "Puericultura", "Para las madres", "Consejos a las madres", "Para las madres de familia", etc.) y de la creación de asociaciones o instituciones femeninas promovidas por la industria cuya finalidad específica era asistir a las madres o tratar temas enfocadas hacia ellas ("Círculo de madres", "Liga de las madrecitas" y "Gota de leche"). En base a los artículos revisados, se establecen deberes esenciales para con los hijos e hijas: la crianza, el cuidado y la preparación de su alimentación, su salud, su educación e, inclusive, construir su carácter. En este aspecto es importante mencionar que todos los artículos relacionados con la

\footnotetext{
51 Rubin, Gayle. 1997. "El tráfico de mujeres: Notas sobre la "economía política" del sexo", en La construcción cultural de la diferencia sexual, México, Programa universitario de estudios de género (PUEG).

52 Montecino, Sonia. 1996. "Identidades de género en América Latina: mestizaje, sacrificios y simultaneidades". En revista Persona y Sociedad. Vol. 10, № 1, Santiago, pp. 189.

53 Ídem.
} 
familia y la crianza de los hijos e hijas iban dirigidos solo hacia las mujeres, apoyando la idea de que era "la razón de ser" de ellas.

Debido a esto, el rol femenino de la madre se ha mantenido en el tiempo y se perpetúa como el más relevante para las mujeres, por su papel de transmisoras de la cultura. Más adelante esto será comprendido por la carbonífera y comenzaron a aparecer artículos haciendo alusión al "rol social" de la mujer, visibilizando un modelamiento a través del discurso del periódico más directo y otorgándole relevancia.

\section{Rol como dueña de hogar}

Imagen 3: Artículo del periódico que presenta la temática de "Rol como dueña de hogar"

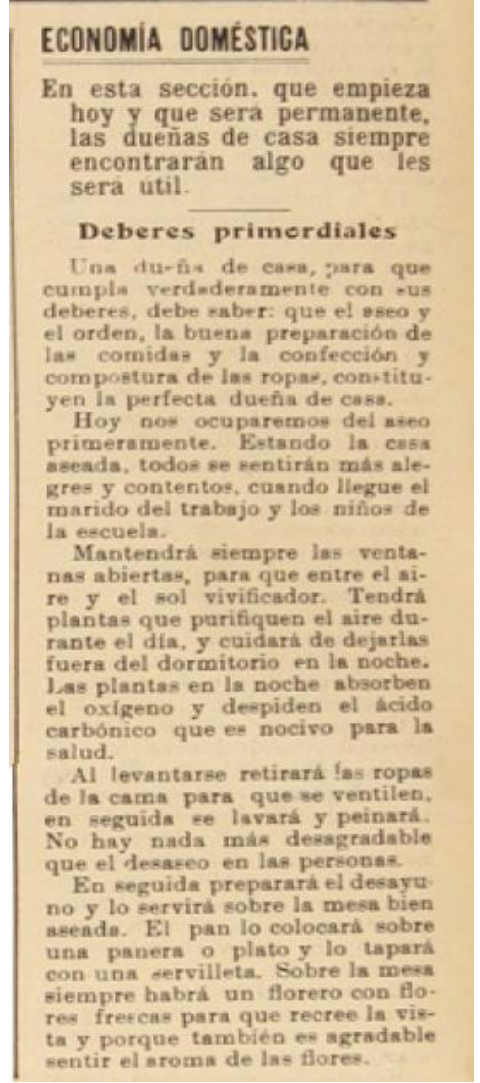

\section{ECONOMÍA DOMÉSTICA}

En esta sección, que empieza hoy y que será permanente, las dueñas de casa siempre encontrarán algo que les sea útil.

Deberes primordiales

Una dueña de cada para que cumpla verdaderamente con sus deberes, debe saber que el aseo y el orden, la buena preparación de las comidas y la confección y compostura de las ropas, constituyen la perfecta dueña de casa.

Hoy nos ocuparemos del aseo primeramente. Estando la casa aseada, todos se sentirán más alegres y contentos, cuando llegue el marido del trabajo y los niños de la escuela.

(...)

Periódico “La Opinión”, núm. 154, 01 de enero 1929. Página 11. Impreso en Concepción.

El segundo rol predominante impuesto para el género femenino en el discurso del periódico era el rol de dueña de hogar (Ver Imagen 3). Este rol fue entendido como el estar a cargo de la familia, del marido (en caso de tener uno) y, por sobre todo, de mantener el hogar en óptimas condiciones. Este rol era complementario al rol de madre, ya que ambos operaban en la misma 
esfera social y espacial (el hogar como espacio casi único de influencia y de interacción). Así, este rol se basaba en tres principios centrales: el aseo del hogar, la alimentación de la familia y la economía del hogar.

El cuidado del hogar era otro de los roles femeninos por excelencia, donde los deberes, como se esbozó más arriba, son claramente definidos: el aseo, limpieza y orden del hogar, la alimentación de su familia y la economía del hogar. Un punto aparte es el tema de la economía en el hogar ya que se consideraba que las mujeres eran las únicas capaces de administrar de la mejor forma posible el salario obtenido por el hombre. Esto era un elemento de gran importancia para la industria ya que, de cierto modo, permitía un manejo económico de las familias. Klubockestablece que junto con promover los matrimonios, el control económico era una medida paternalista común en industrias mineras para mantener el orden en las ciudades industriales (controlando los comportamientos sexuales, erradicando las "distracciones" para los obreros, evitando que permanecieran solteras las mujeres mucho tiempo y manejando los gastos para evitar vicios y excesos) ${ }^{54}$. Para poder ejercer este control económico, la regulación del hogar era esencial, lo que se evidenciaba en las múltiples secciones enfocadas en el cuidado del hogar ("Para las dueñas de casa", "Economía doméstica", "Para las madres de familia" y una gran cantidad de textos moralizantes sobre la importancia del hogar modesto y de la necesidad de economizar). Se llegó a crear una escuela de economía doméstica para mujeres. Así, la industria no solo entregaba el salario de los obreros y establecía los precios de los productos en los Economatos, sino que indicaba, a través del discurso del periódico, cómo y en que este dinero debía ser gastado. Según el periódico, los problemas económicos de las familias y de las ciudades industriales, eran a causa de una mala administración del dinero por parte de las mujeres, trasladando la responsabilidad sobre el bienestar de las personas a los hogares y particularmente a ellas. Si bien los artículos moralizantes apuntaban a ambos géneros, en su mayoría eran dirigidos hacia el género femenino. Lo anterior se evidencia en varios artículos en las secciones dirigidas hacia mujeres, un ejemplo de esto lo podemos ver en siguiente extracto (Ver imagen 4):

54 Klubock. 1995. “Hombres y mujeres en el Teniente, pp. 227. 
Imagen 4: Artículo del periódico que ejemplifica el manejo financiero del hogar por parte de las mujeres

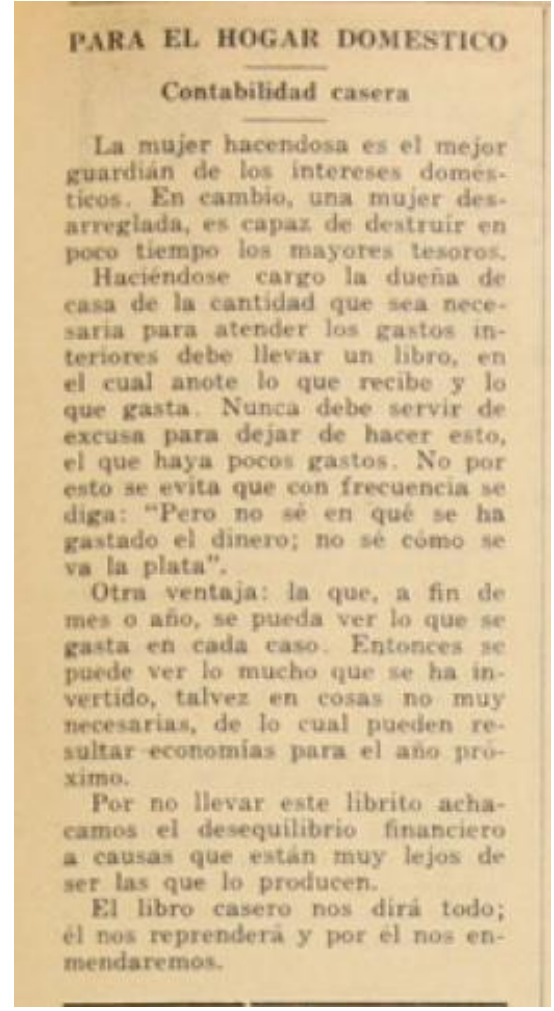

\section{PARA EL HOGAR DOMÉSTICO \\ Contabilidad casera}

La mujer hacendosa es el mejor guardián de los intereses doméstico. En cambio, una mujer desarreglada, es capaz de destruir en poco tiempo los mayores tesoros.

Haciéndose cargo la dueña de casa de la cantidad que sea necesaria para atender los gastos interiores debe llevar un libro, en el cual anote lo que recibe y lo que gaste. Nunca debe servir de excusa para dejar de hacer esto, el que haya pocos gastos. No por esto se evita que con frecuencia se diga: "Pero no sé en qué se ha gastado el dinero; no sé cómo se va la plata".

Periódico “La Opinión”, núm. 128, 05 de enero 1928. Página 5. Impreso en Concepción.

La preocupación por la alimentación, el aseo y la limpieza eran formas de mantener la salud de los obreros y sus familias, de modo que el espacio del hogar se transformó en un medio de influencia de la industria para mejorar las condiciones sanitarias de sus ciudades industriales. La mejora de las condiciones sanitarias incidía en el índice de mortalidad infantil y en cómo las distintas enfermedades afectaban a los obreros. La inasistencia al trabajo, independiente del motivo, era visto como una falta, además del posible efecto negativo sobre los resultados en las actividades productivas. Esto se hace aún más evidente al revisar el concurso de "casas aseadas y balcones adornados" promocionado en "La Opinión", donde mediante revisiones periódicas, se definía una casa cuyo orden y aseo era destacable, llegando a obtener no solo un premio, sino que la aparición en el periódico (Ver Imagen 5) en una fotografía de la familia con el premio recibido (una máquina de coser). 
Imagen 5: Fotografía del periódico que muestra a la familia ganadora del concurso de "casas aseadas y balcones adornados en 1924"

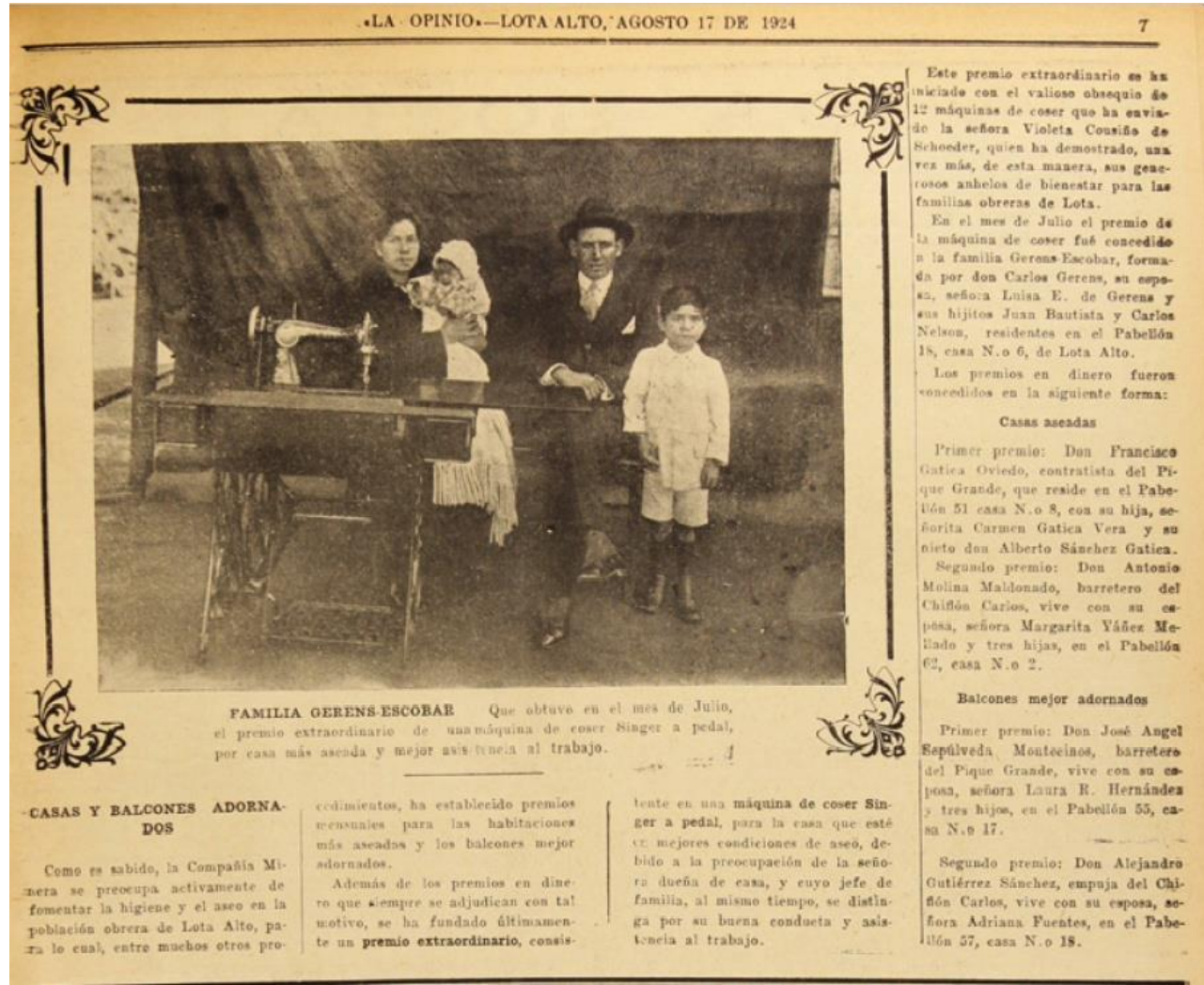

Periódico “La Opinión”, núm. 3, 17 de agosto 1924. Página 7. Impreso en Concepción.

En la Imagen 5 apreciamos que el periódico explicita que la labor del aseo y decoración del hogar, era tarea femenina y además el premio -una máquina de coser-era un objeto "deseado" por mujeres de la época, ya que les permitiría producir artículos para el hogar e incluso generar una fuente adicional de ingresos. En la misma sección se informaba que se premiaba a la familia completa, incluyendo también al hombre de la casa, por su buen comportamiento o asistencia. Así, ambos "buenos comportamientos" eran celebrados por ser los ideales u óptimos esperados para ambos géneros, es decir, se definieron prácticas y/o conductas de la "Familia industrial modelo", extrapolando al ámbito familiar la definición del "obrero modelo". Sobre este concurso, vale la pena mencionar que cuando se mostraban a los y las ganadores, solo se menciona el nombre del hombre y su casa (ejemplo: “Premiado Francisco Valenzuela y su familia, casa $\left.50^{\prime \prime}\right)$, invisibilizando a las mujeres pese a que el premio en cuestión, en su origen, fue destinado hacia ellas. 
El rol masculino en el hogar se definió como el proveedor y el femenino como la administradora, de modo que se mantenía la polarización genérica del espacio público o el "afuera" como territorio masculino y el espacio privado o "adentro" como espacio femenino. Estas esferas estaban muy marcadas y se evidenciaban en los roles de género que se incluían en los artículos del periódico, reproduciendo el imaginario de la "madre presente" y el "hombre ausente" que se explicaba en la sección anterior. De esta forma, la mantención del llamado "hogar modesto" era labor femenina ${ }^{55}$.

\section{Rol como compañera del hombre}

Imagen 6: Artículo del periódico que presenta la temática de "Rol como compañera del hombre" LA MUJER

\section{LA MUJER}

No se puede negar que las mujeres son el mayor placer del hombre en la vida; ellas quitan a su alma el tormento $y$ pesar que reducen cruelmente a la agonia las miserias humanas: consagradas a hacer feliz al hombre que cree en sus bondades y las adora con locura viven solo para el amor; el amor, dulces lazos que atan al hombre al yugo de Himeneo, y le llevan a un Edén dichoso; redimiéndolo si es que ha vivido en un infierno de sufrimientos, condenado en êl para siempre aunque haya creido imposible encontrar la ventura. La mujer con todos los encantos que posee, es la que alumbra la senda del bien y borra la de la eterna condenación del hombre.

NOTA.-Iéase ahora saltando una línea.

No se puede negar que las mujeres son el mayor placer del hombre en la vida: ellas quitan a su alma el tormento y pesar que reducen cruelmente a la agonía las miserias humanas: consagradas a hacer feliz al hombre que cree en sus bondades y las adora con locura viven solo para el amor: el amor, dulces lazos que atan al hombre al yugo de Himeneo, y le llevan a un Edén dichoso: redimiéndolo si es que ha vivido en un infierno de sufrimientos, condenado en él para siempre aunque haya creído imposible encontrar la ventura. La mujer con todos los encantos que posee es la que alumbra la senda del bien y borra la de la eterna condenación del hombre.

\section{NOTA.- Léase ahora saltando una línea}

Periódico “La Opinión”, núm. 315, 01 de agosto 1938. Página 9. Impreso en Concepción.

\footnotetext{
${ }^{55} \mathrm{El}$ "hogar modesto" es una romantización de un hogar donde no se tiene acceso a bienes materiales cuantiosos, es entendido este como un hogar donde no por no tener un poder adquisitivo tan grande, se debe vivir mal o en un lugar en malas condiciones sanitarias. Este es promovido por la carbonífera a través de su concurso de "casas asea das y balcones aseados" y varios artículos de opinión enseñando a las mujeres cómo sacar el mayor partido de sus hogares en base a la buena administración económica, el aseo y la erradicación de la aspiración a tener bienes caros (entendida esta como una costumbre indeseable y de mujeres frívolas). Definición realizada por las autoras en base a la bibliografía y al análisis de los datos.
} 
En la imagen 6 se presenta un ejemplo del tercer rol asignado al género femenino, esto es, como compañera del hombre. En el se evidencia la importancia que se le daba a las relaciones heterosexuales monógamas, que en lo posible debían terminar en matrimonio. Este era la vía idónea para poder concebir y ser madre (rol y deber primordial femenino), y para que el hombre cumpliera con su rol de proveedor de una familia. El rol del género femenino era comprendido como el complemento del masculino en la esfera privada, cumpliendo aquellas tareas que el hombre no podía (por tiempo), ni debía (por construcción de su imaginario masculino) realizar. Es interesante en el artículo de la Imagen 6, como se juega con la dualidad que puede representar lo femenino. Cuando cumple con los mandatos sociales de la buena esposa, compañera y madre, puede ser lo más alto, la luz en la vida de los hombres; de lo contrario se podía convertir en el "mayor tormento y pesar". De alguna manera siempre estaba presente esta dicotomía entre la "buena esposa y madre" y la "mala mujer", actuando de esta manera como un mandato social o como una advertencia sobre el disciplinamiento femenino, por el cual debían velar tanto los propios varones de la familia, como la empresa, a través de sus agentes interventores.

\section{Otros}

En cuanto a otro tipo de temáticas que aparecieron en el periódico, referidos al cumplimiento de los roles femeninos, hubo una gran frecuencia de textos mencionando dos aspectos: 1) cómo debe ser el carácter femenino (ver imagen 7 ) y 2) esbozar ciertas ideas sobre el trabajo femenino.

El carácter femenino "debía" ser siempre afable, alegre, simpático, y debía esforzarse en solucionar cualquier problema de su compañero y de su familia, sin compartir los pesares de su vida individual con estos.

Sobre el trabajo femenino, se indica que las mujeres podían trabajar y que dadas las condiciones económicas existentes no se les debía negar el acceso al trabajo, siempre y cuando este no fuese incompatible con sus labores como madre y compañera del hombre y sus responsabilidades domésticas. 
Imagen 7: Artículo del periódico que presenta la temática de "Otros"

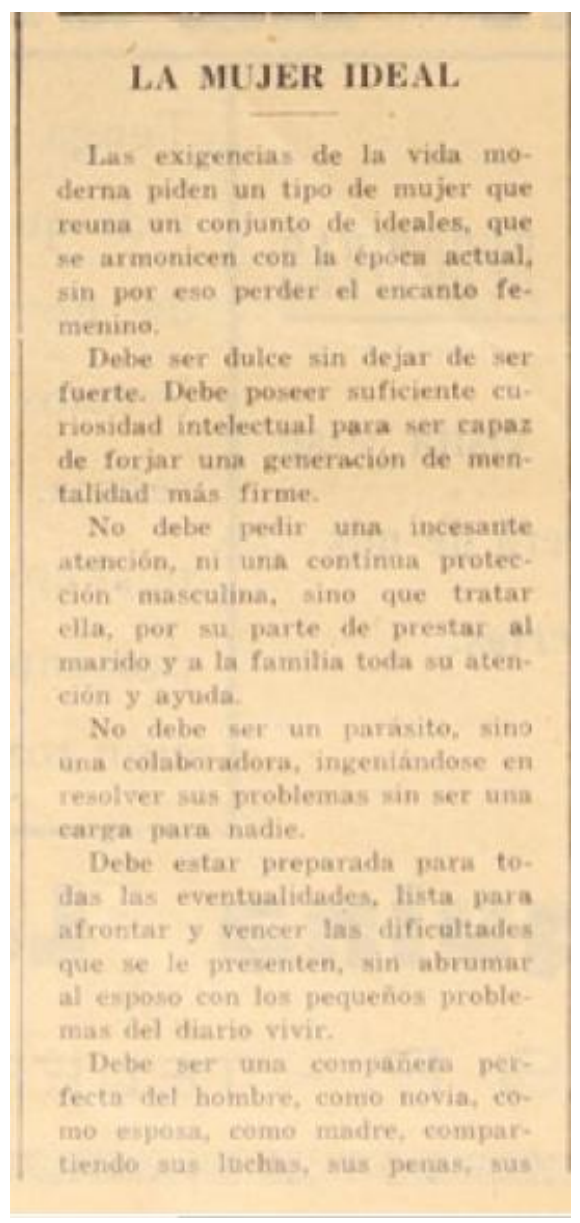

LA MUJER IDEAL

Las exigencias de la vida moderna piden un tipo de mujer que reúna un conjunto de ideales que se armonicen con la época actual sin por eso perder el encanto femenino.

Debe ser dulce sin dejar de ser fuerte. Debe poseer suficiente curiosidad intelectual para ser capaz de forjar una generación de mentalidad más firme.

No debe pedir una incesante atención, ni una continua protección masculina, sino que tratar ella, por su parte de prestar al marido y a la familia toda su atención y ayuda.

No debe ser parásito, sino una colaboradora, ingeniándose en resolver sus problemas sin ser una carga para nadie.

\section{(...)}

Periódico “La Opinión”, núm. 328, 01 de diciembre 1939. Página 10. Impreso en Concepción.

En base a estos tres roles (madre, dueña de casa, esposa-compañera) se articulaba el imaginario de las mujeres en las publicaciones de "La Opinión". Hubo ciertos cambios a través de los años, como la promoción de la incorporación de las mujeres al mundo laboral y la visibilidad que se le dio a las asociaciones femeninas, una tendencia que fue en alza durante la segunda mitad de la vida del periódico, pero en general se mantuvo esta estructura básica. Estos tres roles se complementan entre sí ya que se desarrollan en conjunto y en el mismo espacio: el hogar. Como plantea Figueroa ${ }^{56}$, el espacio de las mujeres en la sociedad lotina

${ }^{56}$ Figueroa. 2009. Revelación del subsole. 
correspondía al opuesto del espacio de influencia masculina, centrado en la mina, el mundo público y el mundo laboral, en términos de la autora, es el "subterra" ${ }^{57}$ o el abajo; mientras que las mujeres se desenvolvían en el "subsole" o el arriba, todo espacio que formara parte de la vida privada de los obreros, que corresponden con sus familias y con sus actividades en tiempos fuera del espacio laboral. En este sentido, el tejido social era obrero-céntrico ${ }^{58}$ (y por ende, centrado en lo masculino) ya que todo giraba en torno a las actividades productivas, que también incluyeron la constitución de las ciudades industriales y las interacciones en espacios de ocio. Las mujeres quedaban relegadas a complementar a sus contrapartes masculinas en aquellas tareas, espacios y deberes fuera del espacio productivo, a cumplir con el imaginario femenino de la época (ser madre) y a poseer un rol aparentemente secundario que comenzó a cobrar importancia (para la industria) más tardíamente, aunque poseían un protagonismo y rol relevante en la sociedad debido a la variedad de tareas que cumplían y que no ha sido reconocida o que fue sistemáticamente invisibilizada por la historia y/o trabajos sobre el mundo industrial.

\section{Discusión}

La presente investigación busca reconstruir la identidad de género femenina como un elemento central en las dinámicas de poder y en las relaciones existentes en la ciudad industrial de Lota. Aunque las mujeres no formaran parte del ámbito productivo minero, su rol como actores sociales encargadas de la esfera privada, del hogar y/o de los espacios de ocio, fue muy relevante dentro del contexto del Paternalismo Industrial. A través de sus múltiples prácticas de disciplinamiento social y/o cultural, las dinámicas sociales, políticas y de poder entre el patrón y la familia industrial trascendieron lo productivo.

El propósito fue comprender las construcciones identitarias de género como un elemento central en el análisis de las dinámicas en la industria de Lota en el siglo XX. Buscamos reconstruir las identidades de género definidas por la Industria Carbonífera de Lota, a través del discurso de un medio de prensa generado por ésta, el periódico "La Opinión". Este medio de prensa fue producido y distribuido por la carbonífera a los trabajadores y sus familias, por lo que su análisis nos permitió desentrañar el discurso que la empresa poseía y buscaba extender a los lectores de este medio de prensa, con el fin de impactar en la vida de quienes habitaron las ciudades carboníferas. Su frecuencia y distribución gratuita, le permitía llegar a más personas, lo que permite teorizar en torno al objetivo central de esta investigación, es decir, a la posibilidad de que este haya sido un mecanismo de disciplinamiento cultural.

\footnotetext{
${ }^{57}$ Concepto utilizado por Consuelo Figueroa como como el central de su libro, acuñado en las novelas de Baldomero Lillo que narra eventos ocurridos en las minas de Lota. "Subterra: cuadros mineros" (1904) y "Sub sole" (1907).

${ }^{58}$ Término utilizado por las investigadoras de este trabajo, no utilizado por Consuela Figueroa.
} 
La creación del periódico fue parte de las acciones, instancias y espacios generados por el Departamento de Bienestar de la carbonífera y consistió en una práctica de control social. Este departamento fue creado con la finalidad explícita de otorgarles "bienestar" a los trabajadores a cambio de disciplina. Lo que implicaba un modelamiento de los sujetos a partir de un férreo control político, social y moral, que iba de la mano con los beneficios que recibían como clase trabajadora. El Departamento de Bienestar buscaba ser un puente entre el mundo laboral y público (el trabajo) y el mundo personal y privado (el hogar, el ocio y la familia) y, así, lograr un control de todos los espacios habitados por los trabajadores, logrando influenciar sus actividades, evitar los vicios y excesos y modelar en ellos los comportamientos y actitudes deseados por la industria y/o el patrón. Las esferas públicas y privadas, con el desarrollo del sistema capitalista se encontraban separadas, pero con el desarrollo industrial y los problemas asociados a su implementación (la llamada "cuestión social") surgió el Paternalismo Industrial como la vía idónea para reconfigurar las relaciones entre patrones/industrias y obreros/trabajadores.

Así, el disciplinamiento ejercido hacia las máquinas, los espacios, los cuerpos y, para fines de esta investigación, las mentes, era entendido como natural para la generación de una industria en la cual se cumplieran los fines del patrón, es decir, que fuera productivamente exitosa. Por este motivo es que se generó un verdadero concepto de "obrero soñado" 59 bajo el cual la industria definió los valores, roles y tareas esperadas y deseadas para sus trabajadores y que se hacían extensivos a toda la familia industrial. Esta definición además consistía en un opuesto dicotómico de los vicios y aspectos indeseables que afectaban la productividad y la estabilidad de la industria (a través de revueltas sociales, levantamientos, vicios, etc.), por lo que el disciplinamiento extensivo aplicado para su erradicación tenía un componente moral que buscaba mantener a los trabajadores aspirando a este imaginario del "obrero soñado" y que además aseguraba su bienestar. Un bienestar que era utilitario para la industria.

El periódico "La Opinión”, en el contexto expresado anteriormente, no solo consistía en un mecanismo de control social indirecto, sino que además era un medio de prensa concreto que cumplía dos funciones: 1) Actuar como palestra o como escenario para visibilizar las buenas acciones y medidas generadas por la industria, buscando explicitar su preocupación por sus trabajadores y generar esta visión de "la buena industria"; 2) Modelar y/o disciplinar a sus lectores y lectoras manejando el contenido de este para sus fines particulares. La carbonífera a través del disciplinamiento extensivo, tenía el control de los espacios de ocio fuera del espacio laboral; es decir, el poder sobre qué compraban, comían, vestían y, en este caso, consumían todos los miembros de la familia industrial. El periódico presentaba un contenido que era

\footnotetext{
59 Referencia al libro de José Sierra Álvarez "El obrero soñado", un trabajo sobre el paternalismo industrial y cómo la industria modela y/o disciplina a sus trabajadores. Sierra. 1990. El obrero soñado.
} 
creado, definido y regulado por la misma industria, actuando como un mecanismo disciplinador para sus lectores/trabajadores.

Las identidades de género estaban bastante definidas y claras en el discurso del periódico, haciendo referencias explícitas a ambos géneros en ciertas ocasiones. El análisis realizado indicó que existía una tendencia del periódico a tratar en base a su género más a mujeres que a hombres, constituyendo el $70 \%{ }^{60}$ del total de textos en los que se hacía referencia a los géneros de las personas de forma explícita. Esto indica que es posible que la identidad masculina haya sido mejor entendida o mayormente definida, mientras que la identidad femenina se constituyó en base a su opuesta y no por sí misma, motivo por el cual se hacía necesario ser concreto en cuanto a qué era lo esperado o deseado para ellas. En general, los tipos de textos que hacen alusión a los géneros fueron diversos, pero cabe mencionar que los textos dirigidos a hombres en su mayoría consistían en indicar cuales roles o valores no eran esperables para estos, y no tanto en indicarles cómo actuar o pensar. Lo cual reforzaba la idea de que la identidad masculina era mejor comprendida, más difundida o conocida y que no necesitaba ser redefinida. La femineidad y la masculinidad de forma general pueden ser explicadas en base a la dicotomía hogar/femenino y trabajo/masculino. La femineidad estaba definida en base a sus roles en las esfera privada, es decir, en el hogar y con la familia, mientras que la masculinidad estaba definida en base a la esfera pública, es decir, el mundo laboral y político principalmente.

La identidad femenina en el periódico se definió en base a tres aspectos centrales: 1) rol de madre, 2) rol como dueña de hogar y 3) rol como compañera del hombre (ver Imagen 8). El rol principal era el de madre, que era transversal a los otros roles y a los otros aspectos. El rol de madre no solo obedecía a construcciones genéricas fomentadas por la industria, sino que obedecía a la construcción de femineidad existente en la época y que perdura hasta nuestros días. La maternidad es un rol que, entendido desde su concepción tradicional, solo puede ser realizado por las mujeres debido a sus capacidades biológicas reproductivas, pero en el contexto del Paternalismo Industrial en general y, en Lota en particular, jugaba un rol políticosocial más profundo. Como se observó, el rol de madre asociado a la procreación le entregaba la facultad a las mujeres de ser quienes transmitían no sólo sus genes y los del padre a sus hijos e hijas, sino que eran las encargadas de la transmisión de los elementos culturales (tradiciones, pensamientos, ideas, etc.). En el contexto del Paternalismo Industrial como estrategia disciplinadora, consistía en la transmisión de la docilidad de carácter y disciplina, además de la visión de la "buena industria" a las generaciones más jóvenes. Su rol de formadoras y educadoras se expandió en lo laboral, por lo que los trabajos esperados para mujeres de la época consistían en formar a los jóvenes (maestras) o en asistir y/o facilitar la capacidad

\footnotetext{
60 Porcentaje generado en base al análisis del periódico.
} 
procreativa femenina y perpetuar el imaginario femenino asociado a la maternidad (enfermeras, matronas, visitadoras sociales, etc.). El rol como dueña de hogar se relacionaba con el primero, ya que constituía el espacio de influencia central en el cual se llevaba a cabo la vida familiar con los hijos e hijas. Además, se les inculcaba que fueran capaces de llevar un "hogar modesto", sano, pulcro y sin desperdicio económico. La influencia de la industria en este espacio era necesaria ya que el hogar como elemento de la vida privada del obrero podía generarle a los trabajadores vicios, problemas de salud y/o problemas económicos derivados. De este modo, el rol de dueña de hogar se relaciona con el rol de compañera del hombre, donde la mujer debía ser la persona que asistía al hombre en todo lo necesario para tener un buena vida y le facilitara el manejo de la vida privada o personal, inclusive sugiriendo la privación de compartir pensamientos, ideas o apreciaciones personales si es que estas eran capaces de generar algún tipo de malestar en su contraparte masculina.

Imagen 8. Esquema resumen de los roles que componen la identidad de género femenina en Lota industrial según el discurso del periódico "La Opinión" de Lota.

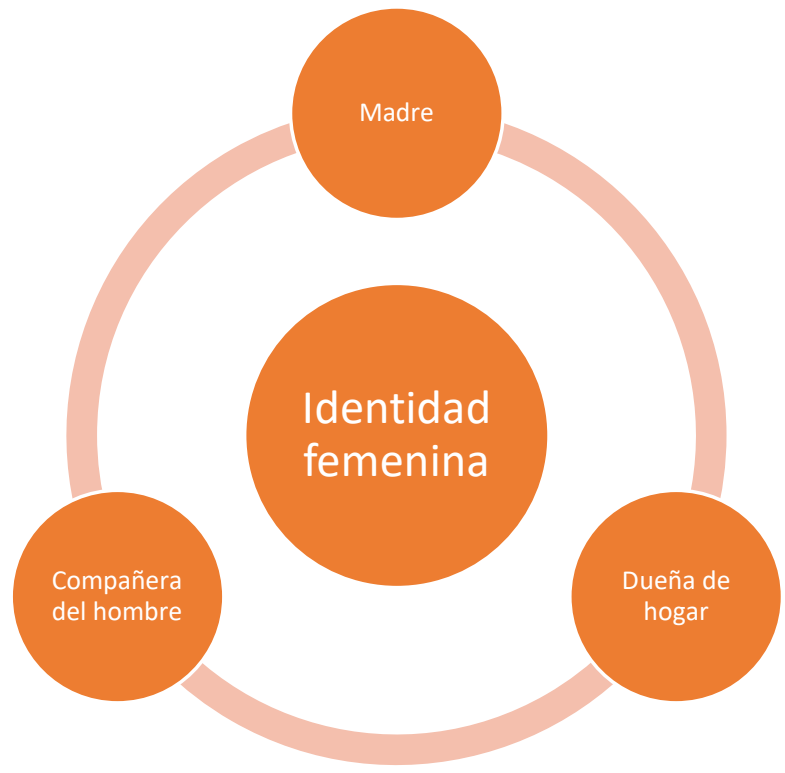

Fuente: elaboración propia.

De esta forma, la identidad femenina se articulaba en base a estos tres roles, siempre de forma utilitaria para los fines de la industria, consistentes en generar trabajadores fuertes, sanos, responsables y, finalmente, productivos laboralmente. El disciplinamiento cultural de las mujeres en base a estos roles aparentemente tradicionales femeninos, que no guardaban 
relación con el trabajo en la mina, eran necesarios para la industria, por lo que su modelamiento cultural, difundido a través del periódico se constituye como uno de los mecanismos para asegurarlo, estableciendo y consolidando los parámetros morales y sociales para que el comportamiento femenino fuera el idóneo, enunciando estos como el medio para ser personas integrales y útiles socialmente.

Sumado a los numerosos artículos moralizantes presentes en el periódico, el rol del Departamento de Bienestar, las asociaciones femeninas y las visitadoras sociales sólo contribuyeron a perpetuar este mecanismo de control social hacia el género femenino. Como se enunció con las asociaciones y las instancias y espacios generados por este departamento, se contribuyó a perpetuar y fomentar los estereotipos de género femeninos que la industria necesitaba.

Distinto es el caso de las visitadoras sociales ya que, si bien su trabajo era de la misma naturaleza de las instancias mencionadas anteriormente, su labor era directa y concreta ya que eran trabajadoras de la industria, lo que les permitía inmiscuirse en la intimidad de los hogares de los trabajadores. A través de la intervención social, permitían el ingreso de la industria en el espacio privado, logrando, finalmente, un real control de todos los espacios donde habitaba el obrero. La visitadora social entendida como un mecanismo de control social ${ }^{61}$ posibilitaba el asistencialismo vertical desde el patrón/industria hacia el obrero y su familia, utilizaba la construcción de redes de confianza y complicidad femenina, como herramienta para mostrar como veían la realidad de los hogares y enfatizar en la necesidad de erradicar aquellos aspectos que eran peligrosos para la estabilidad de la industria, como la mantención de un lugar insalubre para vivir (en caso de que la dueña de casa en cuestión no mantuviera las condiciones de limpieza idóneas) y el abuso doméstico (eran las personas a quienes las dueñas de casa llamaban para "acusar" con la industria a sus maridos que presentaban un mal comportamiento). Al mismo tiempo, la labor de las visitadoras sociales fomentaba la idea de que los trabajos femeninos debían promover los roles femeninos tradicionales (madre, dueña de hogar y compañera del hombre), permitiendo que mujeres asesoraran o ayudaran a otras mujeres con temáticas que debían ser solo vistas por el género femenino (la crianza de los hijos, la salud, el manejo del hogar, la alimentación, etc.). Así se convirtieron en aliadas de las dueñas de los hogares de Lota, cumpliendo su rol como agentes del control social empresarial. Pero también es importante consignar que, gracias a ellas, la vida de las mujeres lotinas pudo haber mejorado en muchos aspectos, sobre todo en el control de la violencia doméstica y el alcoholismo. Vale la pena mencionar que, curiosamente, no aparecen muchos artículos sobre la naturaleza de su trabajo en el periódico, salvo por su llegada a la industria y uno que otro artículo que da cuenta de algún evento organizado por ellas.

Illanes. 2006. Cuerpo y sangre de la política. 
En cuanto a la identidad masculina, estaba definida por el ámbito laboral y su alejamiento de todo aspecto que tuviera que ver con el hogar y la crianza de los hijos e hijas. En general, las referencias al género masculino en el periódico siempre eran negaciones sobre elementos que no formaban parte de su identidad genérica, en ocasiones también existían textos que les indicaban que debían respetar a las mujeres debido a que son como sus madres (nuevamente perpetuando el imaginario de la madre como el motivo de existencia femenino). Cabe mencionar el alto número de textos moralizantes, que guardaban relación con temas políticos y sociales, además de numerosas campañas de concientización sobre los distintos vicios presentes en la vida de los obreros (alcohol, cigarro, relaciones sexuales casuales, etc.). Si bien estos no hacen referencia explícita a ningún género (y por este motivo no fueron analizados en profundidad en cuanto a su contenido en el análisis de la investigación), es relevante mencionar que enunciaban un nacionalismo asociado también a su rol como buenos trabajadores, que buscaba posicionarlos como opuestos a las revueltas sociales a nivel nacional o internacional, lo cual es consistente con la idea de que el discurso del periódico buscaba en esencia mantener la estabilidad de la industria.

Las visitadoras sociales también jugaron un rol importante en la construcción de la identidad masculina, con la finalidad de reportar comportamientos indeseables tratando de restaurar la imagen de un padre de familia más presente, en contraposición de la imagen del padre de familia ausente solo preocupado de su trabajo. Así, el matrimonio también fue un mecanismo de control social que fue promovido por la empresa, ya que era visto como el ideal para la familia industrial. Este permitía asistir al hombre en su erradicación de vicios (teniendo alguien que administre su dinero y lo utilizara para fines relevantes como la mantención del hogar), eliminar las relaciones sexuales casuales (un peligro, tanto para la salud como para la moral) y el ascenso hasta el estado de "obrero soñado", que recibía incentivos por su buen comportamiento.

\section{Conclusiones}

En síntesis, la construcción de las identidades de género desde el discurso del periódico "La Opinión" de Lota puede ser entendida como modelamiento cultural bajo una lógica de paternalismo industrial. Si bien el análisis presentado genera una reconstrucción de las identidades de género existentes en el contexto industrial lotino hasta 1962, la evidencia bibliográfica disponible indicaría que las características del periódico revisado se replican en otros centros industriales que también generaron sus propios medios de difusión de sus ideales de obreros, mujeres y familias industriales ${ }^{62}$. Es de interés para futuras investigaciones, no solo

\footnotetext{
62 Existieron periódicos empresariales en la carbonífera Schwager: La Información; en la siderúrgica Huachipato, Revista Huachipato; en la CRAV-Penco, Revista Pan de Azúcar, en la ENAP de Magallanes, Infórmese, entre otros.
} 
ahondar en las categorías o tópicos presentes como centrales para cada género en el discurso del periódico, sino que realizar un análisis de segundo orden profundizando en las transformaciones que han tenido estos roles, conceptos e identidades de género a través del tiempo y el desarrollo de las dinámicas patrón-obrero y patrón-familia industrial, de las políticas asistencialistas y de su efecto en la sociabilidad obrera, sobre todo con el aumento de la participación política de la clase obrera entre los años $50^{\prime}$ y $70^{\prime 63}$. Este estudio además buscó generar un análisis histórico en base a otro tipo de documentos, ya que en su mayoría la revisión de prensa se realiza de forma referencial y/o complementaria a la revisión de otras fuentes, usualmente no como la fuente central de las investigaciones sobre el proceso de industrialización. En ese sentido esta investigación busca ser un aporte para complementar futuros análisis con enfoque de género sobre la época y período estudiado. Finalmente, esta investigación nos permitió observar el discurso explícito de la industria sobre temas de género durante los 38 años de publicación del periódico, relevando la importancia de generar análisis y reflexiones en torno a las identidades de género en contextos históricos aparentemente no vinculados con el género femenino o con las expresiones de identidades y/o roles de género.

\section{Referencias citadas}

Aróstegui, Julio. 1995. La investigación histórica, teoría y método. Barcelona, Editorial Crítica.

Astorquiza, Octavio y Galleguillos, Oscar. 1952. Cien años del carbón de Lota 1852-1952. Lota, Compañía carbonífera e industrial de Lota.

Bardin, Laurence. 1977. El análisis de contenido. España, Editorial Akal.

Butler, Judith. 2002. Cuerpos que importan. Sobre los límites materiales y discursivos del sexo. España, Editorial Paidós.

Figueroa, María Consuelo. 2009. Revelación del subsole: Las mujeres en la sociedad minera del carbón 1900-1930. Chile, Editorial ICSO Diego Portales.

Foucault, Michel. 2009. Nacimiento de la Biopolítica. Cursos en el "College de France" (1978-1979). España, Editorial Akal.

Godoy, Milton. 2015. "Las casas de la empresa: Paternalismo industrial y construcción de espacio urbano en Chile. Lota, 1900-1950", en Revista Universum, N 1, Vol. 30, Universidad de Talca, Chile, pp. 115-136.

González, Yanko. 2007. "Servicio militar obligatorio y disciplinamiento cultural: Aproximación al caso Huilliche-Mapuche siglo XXI”, en ALPHA, N²4, Chile, pp. 111-137.

Illanes, María Angélica. 2006. Cuerpo y sangre de la política: La construcción histórica de las visitadoras sociales (1887-1940), Chile, Ediciones LOM.

\footnotetext{
63 Videla, Enzo. 2013. "Nuevas fuentes para la Historia de las relaciones sociales de los trabajadores de la Minería del Carbón. 1930-1952. Los Archivos de empresas". ANPUH, Conhecimiento histórico e diálogo social, XXVI Simpósio Nacional de História.
} 
Illanes, María Angélica. 2001. "Ella en Lota-Coronel: poder y domesticación: el primer servicio social industrial de América Latina", en Mapocho Revista de Humanidades y Ciencias Sociales, $\mathrm{N}^{\circ} 49$, Santiago, pp. 141-148.

Klubock, Thomas. 1995. "Hombres y mujeres en el Teniente: La construcción de género y clase en la minería chilena del cobre, 1904-1951", en Godoy, Lorena, Hutchison, Elizabeth, Rosemblatt, Karin y Zárate, M. Soledad (eds.), Disciplina y desacato. Construcción de identidad en Chile, siglos XIX y XX, Editorial SUR/CEDEM. pp. 223-253.

Diario La Opinión (Lota, 1924-1962).

Montecino, Sonia. 1996. "Identidades de género en América Latina: mestizaje, sacrificios y simultaneidades", en Revista Persona y Sociedad, Vol. 10, № 1, pp. 187-200.

Rubin, Gayle. 1997. "El tráfico de mujeres: Notas sobre la "economía política" del sexo", en Lamas, Marta (Comp). La construcción cultural de la diferencia sexual. México, Programa universitario de estudios de género (PUEG), pp. 35-98.

Sennet, Richard. 1982. La Autoridad. España, Editorial Alianza.

Sierra, José. 1990. El obrero soñado: Ensayos sobre el paternalismo industrial (Asturias, 1860-1917). Madrid, Siglo veintiuno editores.

Valdivieso, María Angélica. 2009. "Las mujeres y lo femenino en el discurso historiográfico: su contribución a la memoria y al imaginario social latinoamericano sobre la presencia de las mujeres en el espacio público", en XII Jornadas Interescuelas /Departamentos de Historia. Facultad de Humanidades y Centro Regional Universitario Bariloche, Argentina, Universidad Nacional del Comahue.

Vergara, Ángela. 2013. "Paternalismo industrial, empresa extranjera y campamentos mineros en América Latina: un esfuerzo de historia laboral y transnacional", en Avances del Cesor, Año X, $\mathrm{N}^{\circ}$ 10, Argentina, pp. 113-128.

Videla, Enzo. 2013. "Nuevas fuentes para la Historia de las relaciones sociales de los trabajadores de la Minería del Carbón. 1930-1952. Los Archivos de empresas", en XXVI Simpósio Nacional de História, Conhecimiento histórico e diálogo social, ANPUH, Brasil. 